\title{
SABERES HOY: DISEMINACIONES, COMPETENCIAS $Y$ TRANSVERSALIDADES
}

\author{
Jesús Martín-Barbero (*)
}

SÍNTESIS: La escuela y la familia parecen ser las dos instituciones más afectadas por las transformaciones habidas en los modos de circular el saber, que constituyen una de las más profundas mutaciones que sufre la sociedad contemporánea.

Esta mutación se manifiesta en la circulación de los saberes por fuera de la escuela y de los libros (descentramiento), y por la difuminación de las fronteras que separaban los conocimientos académicos del saber común (diseminación)

La nueva realidad propone una re-definición del sujeto de la educación. Así, el sujeto cartesiano del conocimiento, base de la acción educativa de la escuela actual, deja paso a un individuo que sufre de una constante inestabilidad en su identidad, ya que no le aporta ninguna de las instituciones sociales modernas, como ocurría con la Iglesia o el Estado. Este sujeto educativo se expresa en idiomas no verbales, basados en su sensibilidad y en su corporeidad, y habita los mundos de los códigos tribales, de la pandiIla y de las sectas, desde donde plantea su rechazo a la sociedad.

La configuración social, originada en los cambios en la circulación de los saberes, está re-creando un tipo de competencias culturales y cognitivas que no parecen apuntar en el sentido de las competencias para la generación de rentabilidad y competitividad, predominante en el campo educativo, ahondando la brecha entre los intereses institucionales y la de los sujetos aprendices.

La superación de esta situación pasa, entre otras cuestiones, por la incorporación de una transversalidad que rompa con el prejuicio que separa a las ciencias de las humanidades y por rescatar aquel tipo de saberes que, no siendo directamente funcionalizables son, sin embargo, socialmente útiles, los saberes lógico-simbólicos, históricos y estéticos. Los saberes indispensables.

SÍNTESE: A escola e a família parecem ser as duas instituições mais afetadas pelas transformações ocorridas na maneira de circular o saber, que constituem uma das mais profundas mutações que a sociedade contemporânea sofre.

(*) Asesor de la Fundación Social (Bogotá), miembro del Comité Consultivo de la Federación Latinoamericana de Facultades de Comunicación Social (FELAFACS) y miembro de la Comisión de Políticas Culturales del Consejo Latinoamericano de Ciencias Sociales (CLACSO). 
Esta mutação se manifesta na circulação dos saberes por fora da escola e dos livros (descentralização), e pelo desaparecimento das fronteiras que separavam os conhecimentos acadêmicos do saber comum (disseminação). A nova realidade propõe uma redefinição do sujeito da educação. Assim, o sujeito cartesiano do conhecimento, base da ação educativa da escola atual, dá passagem a um indivíduo que sofre de uma constante instabilidade em sua identidade, já que nenhuma das instituições sociais modernas tem algo a Ihe oferecer, como acontecia com a Igreja ou o Estado. Este sujeito educativo se expressa em idiomas não verbais, baseados em sua sensibilidade e em sua corporeidade, e habita os mundos dos códigos tribais, das quadrilhas e das seitas, a partir de onde manifesta sua rejeição à sociedade.

A configuração social, originada nas mudanças na circulação dos saberes, está recriando um tipo de competências culturais e cognitivas que não parecem apontar no sentido das competências para a geração de rentabilidade e competitividade, predominante no campo educacional, abrindo a brecha entre os interesses institucionais e a dos sujeitos aprendizes.

A superação desta situação passa, entre outras questões, pela incorporação de uma transversalidade que termine com o preconceito que separa as ciências das humanidades, e por resgatar aquele tipo de saberes que, não sendo diretamente funcionais são, no entanto, socialmente úteis, os saberes lógico-simbólicos, históricos e estéticos. Os saberes indispensáveis.

\section{DESCENTRAMIENTO Y DISEMINACIÓN}

Desde la perspectiva histórica, el conocimiento está llenando el lugar que ocuparon, primero, la fuerza muscular humana, y después las máquinas. Ello implica que en el estrato más profundo de la actual revolución tecnológica lo que encontramos es una mutación en los modos de circulación del saber, que fue siempre una fuente clave de poder, y que hasta hace poco había estado conservando el carácter de ser, a la vez, centralizado territorialmente, controlado a través de determinados dispositivos técnicos y asociado a muy especiales figuras sociales. De ahí que las transformaciones en los modos en que circula el saber constituyan una de las más profundas mutaciones que una sociedad puede sufrir. Por lo disperso y fragmentado que es el saber, escapa de los lugares sagrados que antes lo contenían y legitimaban, y de las figuras sociales que lo detentaban y administraban. Cada día más estudiantes testimonian una simultánea y desconcertante experiencia: la de reconocer lo bien que el maestro se sabe su lección, y, al mismo tiempo, el desfase de esos saberes-lectivos con relación a los saberes-mosaico que sobre biología o física, filosofía o geografía, circulan fuera de la escuela. $Y$ frente a un alumnado cuyo medioambiente comunicativo lo 
«empapa» cotidianamente de esos saberes-mosaico que, en forma de información, circulan por la sociedad, la escuela como institución tiende sobre todo al atrincheramiento en su propio discurso, puesto que cualquier otro tipo de discurso es contemplado como un atentado a su autoridad.

Examinemos esos dos cambios claves. Descentramiento significa que el saber se sale de los libros y de la escuela, entendiendo por escuela todo sistema educativo desde la primaria hasta la universidad. El saber se sale ante todo del que ha sido su eje durante los últimos cinco siglos: el libro. Un proceso que casi no había tenido cambios desde la invención de la imprenta sufre hoy una mutación de fondo con la aparición del texto electrónico. Que no viene a reemplazar al libro sino a des-centrar la cultura occidental de su eje letrado, a relevar al libro de su centralidad ordenadora de los saberes, centralidad impuesta no sólo a la escritura y a la lectura sino al modelo entero del aprendizaje por linealidad y secuencialidad implicadas en el movimiento de izquierda a derecha y de arriba a abajo que aquellas estatuyen. Es sólo puesto en perspectiva histórica que ese cambio puede dejar de alimentar el sesgo apocalíptico con el que la escuela, los maestros y muchos adultos, miran la empatia de los adolescentes con los medios audiovisuales, los videojuegos y el computador. Estamos ante un descentramiento culturalmente desconcertante, pero cuyo desconcierto es disfrazado por buena parte del mundo escolar de forma moralista, esto es, echándole la culpa a la televisión de que los adolescentes no lean. Actitud que no nos ayuda en nada a entender la complejidad de los cambios que están atravesando los lenguajes, las escrituras y las narrativas. Que es lo que en realidad está en la base de que los adolescentes no lean, en el sentido en que los profesores siguen entendiendo leer, o sea sólo libros.

Segundo, des-localización/des-temporalización: los saberes escapan de los lugares y de los tiempos legitimados socialmente para la distribución y el aprendizaje del saber. Desde los faraones a los señores feudales, «la morada de los sabios» estaba cerca del palacio/castillo o se comunicaba entre ellos en secreto. Y también el tiempo de aprender se hallaba acotado a una edad, lo que facilitaba su inscripción en un lugar y su control vital. No es que el lugar escolar fuera a desaparecer, pero las condiciones de existencia de ese lugar estaban siendo transformadas radicalmente, no sólo porque ahora tenían que convivir con un montón de saberes-sin-lugar-propio, sino porque el aprendizaje se había desligado de la edad para tornarse continuo, esto es, a lo largo de toda 
la vida. Los miles de ancianos que estudian hoy en Europa en la universidad a distancia son la prueba más clara del desanclaje que viven los saberes tanto en su contenido como en sus formas.

La des-localización implica la diseminación del conocimiento, es decir, el emborronamiento de las fronteras que lo separaban del saber común. No se trata sólo de la intensa divulgación científica que ofrecen los medios masivos, sino de la devaluación creciente de la barrera que alzó el positivismo entre la ciencia y la información, pues no son lo mismo pero tampoco lo opuesto en todos los sentidos. La diseminación nombra el movimiento de difuminación tanto de las fronteras entre las disciplinas del saber académico como entre ese saber y los otros, que ni proceden de la academia ni se imparten en ella de manera exclusiva. Una pista clave para evaluar esto es la trazada por el sociólogo alemán Ulrik Beck, cuando liga a la expansión ilimitada del conocimiento especializado el paso de los peligros que conllevaba la modernización industrial a los riesgos que entraña la sociedad actual. No hay salida del mundo del riesgo con base en puros conocimientos especializados; más bien sucede al revés: a mayor cantidad de conocimiento especializado, mayores riesgos para el conjunto de la humanidad, desde la biología ambiental a la genética. La única salida se halla en la articulación de conocimientos especializados con aquellos otros que provienen de la experiencia social y de las memorias colectivas.

\section{LOS SUJETOS DE LA EDUCACIÓN}

En el racionalismo moderno el sujeto se identificó con el sujeto del conocimiento, que acuñara Descartes al identificar el conocimiento con aquello que da realidad y sentido a la existencia humana. En tal sujeto la capacidad de reflexionar sobre su propio saber proviene de un gesto de separación radical entre mente y cuerpo: el axioma «pienso, luego existo», es la postulación de un yo autónomo por relacionarlo con todas las demás dimensiones de la vida, y, en especial, de las corporales, sean pasiones o sentimientos, fobias o afectos. El sujeto moderno del conocimiento es definido así en un espacio de relaciones geométricas, pero sin profundidad de campo, similar al efecto de realidad en la pintura renacentista; la racionalidad del conocimiento propicia una sensación de realidad más fuerte que la realidad misma: ¿no identificó Hegel lo real con lo racional y viceversa? En la medida en que lo que se ve es lo real, el ojo del observador desaparece como si no hubiera un punto de vista ni un sujeto que mira, y es entonces cuando 
el mundo del sujeto resulta autoconstituido por su propia capacidad de pensar, de razonar. Es esa pretendida autonomía la que hace crisis, convirtiéndose en rechazo a la razón totalizadora y a su sujeto: el cógito en el que se funda la modernidad.

Esa en apariencia divagación filosófica pone sobre el tapete, y en debate, la soterrada base sobre la que la inmensa mayoría de los maestros en nuestras escuelas, desde la primaria hasta la universidad, construye la visión que tiene de sus alumnos en cuanto sujetos del aprender. Y ello ¡hoy!, cuando el sujeto real que habita nuestras escuelas primarias, secundarias y universitarias no tiene nada que se asemeje a la estabilidad del sujeto cartesiano. La identidad del sujeto que habita nuestro mundo occidental -ya sea en Occidente o en los países a los que Occidente ha ido imponiendo su huella a través de la tecnología- es la de un individuo que sufre una constante inestabilidad sobre su identidad y una fragmentación de la subjetividad cada día mayor. Gente tan poco postmoderna como Habermas acepta que en nuestras sociedades, donde ya no hay una instancia central de regulación y autoexpresión -como lo fueron la Iglesia y el Estado-, tanto las identidades individuales como las colectivas se hallan sometidas a la oscilación del flujo de los referentes y de las interpretaciones, ajustándose a la imagen de una red frágil, casi sin centro ni estabilidad. Stuart Hall, el gran heredero de la investigación cultural en Inglaterra, plantea la necesidad de asumir este cambio estructural que está fragmentando los paisajes culturales de clase, pues "¿qué es la identidad de clase cuando la identidad de género, de etnia, de nación y región, que en el pasado nos habían proporcionado sólidas localizaciones como individuos sociales, hoy día se ven transformadas en la experiencia que de ella tienen los individuos»? Es decir, estamos ante un sujeto cuya autoconciencia es muy problemática, porque el mapa de referencia de su identidad ya no es uno solo, pues los referentes de sus modos de pertenencia son múltiples, y, por tanto, es un sujeto que se identifica desde diferentes ámbitos, con diferentes espacios, oficios y roles. Hoy día una mujer no es sólo la madre de sus hijos ni la esposa de su marido; es, además, una profesional que tiene su propia visión del mundo, su propia posición en términos políticos, ideológicos y estéticos, y cada una de esas afiliaciones significa una desestabilización del sujeto desde el que hablaba un yo de ama de casa-madre de familia. De ello da testimonio cotidiano la crisis de muchas mujeres que a los 45 años y con los hijos ya grandes, se encuentran en un mundo para el que no se prepararon, y en el que aun teniendo mucha vida por delante, no saben qué hacer con ella ¿Qué significa ser mujer sólo en términos de relación familiar cuando los hijos ya 
no responden a la familia patriarcal y la figura del padre se desdibuja como referente aplastante como constructor de la identidad del hijo? Hoy nos encontramos con un sujeto mucho más frágil, más quebradizo, pero paradójicamente mucho más obligado a asumirse, a hacerse responsable de sí mismo, en un mundo en el que las certezas en los planos del saber, como en el ético o el político, son cada vez menores.

Con este sujeto es con quien tiene que lidiar la educación: el de un adolescente cuya experiencia de relación social pasa cada día más por su sensibilidad, por su cuerpo, ya que es a través de ellos que los jóvenes -que hablan muy poco con sus padres- les están diciendo muchas cosas a los adultos mediante otros idiomas: los de los rituales del vestirse, del tatuarse y del adornarse, o del enflaquecerse conforme a los modelos de cuerpo que les propone la sociedad por medio de la moda y de la publicidad. No son sólo femeninos los millones de adolescentes que sufren gravísimos trastornos orgánicos y psíquicos de anorexia y bulimia, atrapados en la paradoja señalada de que mientras la sociedad más les exige que se hagan cargo de sí mismos, no les ofrece una mínima claridad sobre su futuro laboral, profesional o moral.

De ahí que los jóvenes se muevan entre el rechazo a la sociedad y su refugio en la fusión tribal. Millones de jóvenes a lo largo del mundo se reúnen sin hablar, sólo para compartir la música, para estar juntos gracias a ella y a la empatia corporal que genera. Esa palabrita que hoy denomina una droga, el éxtasis, se ha convertido en el símbolo y en la metáfora de una situación extática, esto es, del estar fuera de sí, del estar fuera del yo que le asigna la sociedad y que los jóvenes se niegan a asumir, no porque sean unos desviados sociales sino porque sienten que la sociedad no tiene derecho a pedirles una estabilidad que no confiere ninguna de las grandes instituciones modernas: la política, el trabajo y la escuela atraviesan su más honda y larga de las crisis... de identidad ¿Qué es la política cuando la corrupción ha llenado el vacío ideológico, la ausencia de densidad simbólica de los partidos y la incapacidad de convocatoria? Los partidos se corrompieron cuando se vaciaron ideológica y simbólicamente, y no fue al revés, como pretende una fuerte corriente politicista ¿Y qué ejemplo están dando las generaciones mayores a los jóvenes en términos de ética, de fidelidad, de solidaridad, cuando lo que sus hijos ven crecer y reinar por todas partes es el afán de la riqueza fácil y el conformismo irresponsable?

Mientras el sujeto del aprendizaje emerge de ese entorno fuertemente corporal y emocional, la escuela le exige dejar fuera el 
cuerpo de su sensibilidad porque estorba y sus emociones desestabilizan la autoridad de los profesores. De ahí que el mundo donde el sujeto joven habita no sea menos la escuela que la pandilla, el ghetto, la secta y los mundos de la droga. Desde ahí nos miran y nos oyen nuestros sujetos de educación.

\section{COMPETENCIAS, HÁBITUS Y PRÁCTICAS}

Existe un concepto que, venido del campo de la lingüística y de las teorías de la comunicación, hegemoniza cada vez con más fuerza el ámbito educativo; es el concepto -y el dispositivo- de competencia, cuya aparición en la academia se produjo -y no por casualidad- al mismo tiempo que hacía su entrada en el ámbito de la empresa, en la reingeniería de las empresas. Cuando Chomsky elabora en los años setenta la teoría de la gramática generativa, lo hace avanzando sobre la propuesta de Saussure de dividir analíticamente el idioma en lengua y habla, pero dedicando su estudio únicamente al sistema de signos que es la lengua. Chomsky avanza al proponer una lingüística del habla, distinguiendo en ella la competencia, que es la capacidad que desde muy pequeños tienen los humanos de entender frases nuevas y de producir mensajes nuevos, inéditos; y la performance, la actuación, la realización de esa capacidad, entendiendo y produciendo mensajes nuevos con una vieja lengua. Al mismo tiempo que desde la lingüística el concepto de competencia entraba en el campo de la comunicación mediante el concepto de competencia comunicativa, en el mundo empresarial va a hacer carrera otro concepto de competencia, aquel que liga las destrezas del saber-hacer con la capacidad empresarial de competir, esto es, de ganarle a los otros competidores en la capacidad de producir rentabilidad. Mientras que el primer ámbito, la competencia, se halla asociado a la idea de destreza intelectual, y ésta a la de innovación, y por tanto a la creatividad, en el mundo de la reingeniería empresarial competencia habla de otra cosa: de las destrezas que generan rentabilidad y competitividad. De ahí que en la sociedad actual la significación hegemónica de competencia sea todo lo contrario a la solidaridad. En nuestra América Latina tenemos en el TLC y en el MERCOSUR la más explicita demostración de que los grupos de países que se asocian en espacios de libre comercio, al mismo tiempo que generan asociaciones también lo hacen de exclusiones, pues están hechos para competir en un mercado global en el que la competitividad se impone sobre la solidaridad regional. Entonces, no resulta extraño que en el campo educativo la idea de competencia que predomina sea aquella que se mueve en la lógica del competir más que en las dinámicas del 
crear, aquella que supedita la capacidad de innovar a la de rentar, y que liquida la creatividad social que está en la base del concepto de competencia lingüística y comunicativa. No se puede usar el concepto de competencia sin saber que se está trabajando con un concepto muy ambiguo, ya que estamos nombrando a la vez la creatividad social y la lucha empresarial a muerte por la rentabilidad.

Si queremos recuperar el concepto de competencia en su sentido cognitivo, habría que asociarlo a otros dos: el de hábitus en el pensamiento de P. Bourdieu, y el de práctica en el de Michel de Certeau. Para Bourdieu, el concepto de hábitus se define como competencia cultural, o sea, como «un sistema de disposiciones durables que, integrando las experiencias pasadas, funciona como matriz de percepciones y de acciones posibilitando tareas infinitamente diferenciadas». Es decir, la competencia cultural del hábitus, que es la que nos interesa en términos educativos, hace parte del sistema de disposiciones que hay en el sujeto del aprendizaje, en el que se integran sus experiencias, su trayectoria cultural, o los modos de adquirir esas disposiciones. El hábitus tiene que ver con la forma en que adquirimos los saberes, las destrezas y las técnicas artísticas: la forma de adquisición se perpetúa en las formas de los usos, repite Bourdieu. No se aprecia el piano del mismo modo por alguien que nunca tuvo que ver con uno que por alguien que nació en una casa donde había un piano en el que alguno de sus padres o hermanos tocaba cotidiana o festivamente. Por muchos discos de piano que oiga el primero, la relación con éste instrumento es muy distinta de aquel en cuya casa de niño se oía tocarlo. El modo de relación con los objetos, con el lenguaje o con los saberes, depende de su modo de adquisición.

La cultura oral es también un modo de relación con el lenguaje, que se ha visto desvalorizado por su clasista identificación con el analfabetismo y la incultura. Sin embargo, en el pueblito castellano en el que viví de niño aprendí que en la vida cotidiana de la gente la oralidad podía ser otra cultura: cuando los campesinos de mi pueblo hablaban de su mundo agrario y de cosechas, de sus trabajos y saberes, tenían una riqueza de vocabulario precisa y preciosa; pero si uno les pedía que escribieran... entonces se quedaban mudos, porque la escritura implicaba otra cultura. Y si no escribían no era porque no hubieran aprendido a leer o a escribir, sino porque aprendieron a leer en y para las tareas escolares y no para la vida, como nos descubrió hace ya muchos años Paulo Freire. ¿Qué significa eso? Que el modo de relación con la escritura puramente formal, como ocurre aún en Latinoamérica 
en la mayoría de nuestras escuelas, no es capaz de crear el hábitus de la cultura escrita. Y algo peor: el uso escolar de la cultura letrada puede destruir la cultura oral sin generar el hábitus de leer y de escribir. Un joven psicólogo de la Universidad Javeriana de Bogotá, que hacía una investigación en un barrio de invasión -como se llaman en Colombia los barrios donde llegan los desplazados por falta de trabajo en el campo o por la guerra- me contó que muchos niños de la costa Caribe que habían ido a parar a las frías alturas de Bogotá, se encontraban, además de despojados de su mundo Caribe, de su tierra caliente y sonora, arrojados a una ciudad gris y fría, y con una escuela en la que los maestros les ponían a hablar como se escribe. Resultado: estos niños de la costa, que llegan con el vocabulario vivo de su tierra y una enorme competencia narrativa, al año de estar en la escuela los pierden ambos, porque el maestro quiere que hablen como escriben y el habla de esa costa no cabe en la gramática escrita. De modo que, con las imperfecciones gramaticales, pierden también la riqueza de su vocabulario y su viva competencia narrativa. ¿Dónde queda entonces la identidad de esos niños, el derecho a su diferencia? La escuela cree estar educando, cuando lo que está haciendo es castrar culturalmente a esos niños. Y agregaba el joven psicólogo: ¿cómo es posible que todavía hoy la enseñanza del idioma se haga contra la creatividad que estos niños traen a la escuela? Una escuela incapaz de asumir esa creatividad, y menos de potenciarla, incapaz de diferenciar entre las lógicas de lo oral y de lo escrito, que impone una sola lógica destruyendo quizás para siempre toda posibilidad de que en la vida de esos muchachos y muchachas haya creatividad. Y perder la única creatividad que les quedaba -la de contar sus historias en su vocabulario- puede significar malograr la oportunidad de ser ciudadanos para el resto de sus vidas. Ah, pero eso sí, la escuela les inculcó las competencias de lenguaje con las que podrían competir... ¡Qué mascarada!

La competencia que nos interesa como maestros o profesores tiene mucho más que ver con la competencia cultural de que nos habla Bourdieu, ligada al capital simbólico de una clase social, que no es el mismo en el mundo rural que en el urbano, ni entre la gente que lleva muchos años viviendo en la ciudad que la que lleva pocos, o en una familia patriarcal que en otra en la que los dos padres trabajan fuera de la casa y se tratan como iguales. Y es el capital cultural, ese capital simbólico que emerge de la trayectoria de vida, el que va a ir configurando el hábitus, ese sistema de disposiciones durables, que, a través de experiencias y memorias, va a posibilitar o a obstaculizar la creatividad, la capacidad de innovación de los sujetos. 
El otro concepto que me parece fundamental para redefinir las competencias cognitivas es el de práctica de Michel de Certeau. Al tratar de entender la cultura cotidiana de la mayoría, la del ama de casa, la del obrero de la construcción o la del empleado de comercio, de Certeau toma como claves de su definición los saberes que contienen y posibilitan nuevos haceres. Asi, saber cocinar, saber tejer, saber caminar por la ciudad, saber habitar la propia casa, saber comunicar. Y lo conceptualiza a través de dos caracterizaciones. Primera, los esquemas de operación: en el fondo de toda operación hay un esquema mental sin el cual dicha operación no es posible, como en el fondo de todo buen pianista hay muchas horas de técnica que llegan hasta que pasa a los dedos y ya no se necesita mirar las teclas, porque los dedos aprendieron a leerlas en el pentagrama. Segunda, los operadores de apropiación, que responden a cuestiones de este tipo: ¿cómo hace la gente para saber moverse en la ciudad? Hoy hay en Colombia millones de campesinos que se han visto forzados a dejar su tierra, su labranza, su mundo cultural, y sobreviven en las ciudades no por saberes de ciudad, que los mira como a extraños y por tanto peligrosos, sino por reciclaje de sus saberes rurales: carpintería, zapatería, albañilería, etc. Es con base en esos saber-haceres que traen del campo, saberes orales transmitidos aún de padres a hijos, que son capaces de apropiarse y de tornar útiles los restos, los pedazos de cosas que desecha una sociedad del derroche. Muchos desplazados sobreviven reciclando, desde sus viejos saberes, unos aparatos que cada día se quedan más rápidamente viejos, rediseñándolos, devolviéndoles utilidad social.

Sólo un concepto de competencia arrancado a la obsesión competitiva de la sociedad de mercado, y redefinido desde las competencias culturales del hábitus y de la práctica, podrá ayudarnos a transformar nuestros modelos de enseñanza poniéndolos en una densa relación con las competencias de aprendizaje que los nuevos sujetos Ilevan a la escuela.

\section{TRANSVERSALIDADES: DE LA TOPOGRAFÍA A LA ANTROPOLOGÍA}

En la investigación, la transdisciplina nombra los nuevos problemas de frontera que rebasan el saber especializado. Se trata de una encrucijada de agendas y de enfoques que está exigiendo superar la mera agregación de saberes y de resultados. Lo que se pone en juego es la capacidad de las instituciones académicas de rebasar, en la docencia como en la investigación, el plano de la renovación de contenidos o de 
técnicas, y afrontar el rediseño de los modos de producción del conocimiento, rediseño requerido hoy por una sociedad cuya compresión emborrona las fronteras de los saberes instituidos, al tiempo que desestabiliza las figuras profesionales establecidas. Transdisplinaridad significa, de un lado, la des-jeraquización de los conocimientos para que sea posible dar cuenta de las dinámicas y transformaciones sociales, y, de otro, la asunción de la pluralidad de los discursos y lenguajes sociales - desde la abstracción científica a la ficción literaria, pasando por la crónica y el relato de vida, el lenguaje escrito, el audiovidual y el hipertextual-, como diversos modos de acceso a y de expresión de la irreductible multidimensionalidad de lo social.

Pero la transversalidad va más lejos que la nueva topografía de la transdiciplinaridad, abriéndonos al sentido antropológico de hibridación; híbridaciones no sólo de diferentes tipos de saber sino de distintas racionalidades y lenguajes. En los últimos años el trabajo de Manuel Castells nos está ayudando a entender lo que en el nuevo modo de producir se halla inextricablemente unido a un nuevo modo de comunicar, convirtiendo el conocimiento en una fuerza productiva directa: «lo que ha cambiado no es el tipo de actividades en las que participa la humanidad, sino su capacidad tecnológica de utilizar como fuerza productiva lo que distingue a nuestra especie como rareza biológica, su capacidad para procesar símbolos», con lo cual no se está afirmando que sea en la tecnología donde se halle la solución mágica a nuestros problemas políticos o sociales per se, sino que es por la tecnología por donde pasa en gran medida la creatividad de las sociedades occidentales. Eso implica -frente a tanto discurso que hace de Internet el monstruo que terminará aislando al adolescente, absorbiéndole el cerebro, volviéndolo insolidario y asocial- que los adolescentes solitarios o antisociales no son efecto de Internet sino de una sociedad insolidaria y competitiva, individualista y neorrica, que ellos asimilan desde su experiencia familiar y escolar. Lo que los vuelve insolidarios no es Internet sino una escuela que les pone a competir más que a convivir y a innovar. Lo que de verdad nos plantea hoy la tecnología no tiene nada que ver con lo que predican los pseudoprofetas tecnológicos ni con los miedos de los apocalípticos, que creen que la tecnología está acabando con la civilización occidental.

En sus obras La era de la información y La galaxia Internet, Castells nos asoma a los cambios que Internet está introduciendo en nuestros modos de organizar y de acceder al conocimiento, y, sobre todo, en nuestras maneras de producir conocimiento, pues frente a la 
separación entre mente y cuerpo, entre el hemisferio izquierdo y el derecho del cerebro, entre el hemisferio de la razón argumentativa y el de la emoción, la pasión y el afecto, entre el hemisferio de la escritura y el de la imagen y la música, Internet escribe a la vez con letras, con sonidos y con imágenes. Esto marca el inicio de otra época, de un cambio de época. Ha sido un historiador de la escritura y de la lectura, Roger Chartier, el que ha afirmado que con lo que hay que comparar Internet no es con la imprenta, porque ella nació para divulgar lo que ya estaba escrito -Gutenberg le asignaba la función de hacer que la Biblia llegara a todos los países y a toda la gente- sino con la invención del alfabeto que posibilitó la escritura, pues Internet no es sólo un difusor de viejos saberes, de libros ya escritos, sino un nuevo modo de escribir y de producir saber. Internet no es la causa sino el resultado de la transformación del sujeto humano, la proyección de un nuevo sujeto de conocimiento, que, a su vez, implica el surgimiento de un nuevo ciudadano. Ese nuevo ciudadano se reunió en número de ochenta mil en Porto Alegre, venido de todos los rincones del mundo, de todas las religiones, de todos los oficios y sexos. Ochenta mil personas que se reunieron en buena medida gracias a que Internet les permitió «estar juntos» antes, al posibilitarles poner en común miedos y rabias, demandas y proyectos de una sociedad y de un mundo nuevos, a partir de las luchas de ecologistas y sindicalistas, y hasta de asociaciones tan poco previsibles como la de mujeres norteamericanas de la tercera edad antiglobalización. Lo que se reunió en Porto Alegre fue la diversidad actual de sujetos humanos. De gente que quiere cambiar esta sociedad injusta, en la que Internet es usado por el capitalismo no para unir y sí para dividir, y lo utiliza demostrando las posibilidades de cambiar el mundo, que está siendo secuestrado y castrado por la lógica de los usos mercantiles. Internet replantea también las separaciones radicales de la escuela entre lo que es ciencia, lo que es arte y lo que es técnica. Porque hoy la técnica es interfaz entre la ciencia y el arte. Nunca la ciencia estuvo más cerca del arte, y nunca el arte estuvo más cerca de la ciencia. Hace muchos años que Bachelard planteó que la imaginación humana era sólo una, que comparten el poeta y el científico, el físico y el músico, el bailarín y el ingeniero.

La transversalidad habla en primer lugar de esto: no podemos seguir educando a partir del prejuicio que separa como si fuera un destino fatal a los poetas de los científicos, con lo que ni la ciencia ni la técnica hacen parte de lo que la escuela entiende por cultura, que serian las bellas letras y las bellas artes. Y así nos va en Latinoamérica: tenemos varios premios Nobel de literatura, pero ¿cuántos Nobel tenemos de física, de química, o al menos de economía? Ello se debe en 
gran parte a que desde la escuela se nos ha enseñado que los creativos son los poetas, y los científicos son otra cosa: disciplinados, rigurosos. De esta manera se forma el círculo de que sólo los científicos tienen que ver con la técnica, que tiene que ver con el mercado y el mercado con la competitividad. Entonces los humanistas viven dedicados a criticar el mercado como los tecnócratas a vivir de él. Así no funciona ni la cabeza de nuestros sujetos aprendices ni la sociedad real. Pero tal es la forma en que sigue funcionando la escuela.

Y ello cuando lo propio de la sociedad en la que nos encontramos consiste en unas tecnologías que hacen de mediadoras, de interfaces entre artes y ciencias, entre trabajo y juego. Hoy la tecnología ya no es puntual, nos atraviesa de punta a punta tanto espacial como temporalmente; desde que queremos llevar a un niño al kinder o si tenemos que dar un montón de información para ponerla en el computador de la escuela, eso nos parece lo más normal, pues la institución necesita saber de qué está enfermo, qué problemas ha tenido, etc. Pero en ese acto estamos poniendo una preciosa información familiar en una tecnología institucional que puede transmitirse a los comerciantes y a los bancos o a la policía. La capacidad de la tecnología de transformar la sociedad va en muchos sentidos, tanto creativos como destructivos, pero lo cierto es que hoy no sabemos para dónde va. Pero sí sabemos algo: que no podemos dejársela a esos pocos que se creen los dueños del mundo, porque dominan la tecnología secuestrando sus diversas posibilidades y usos en su propio beneficio y en función de dominar a las mayorías.

La transversalidad apunta aún más lejos: allí donde la tecnobiología parecería capaz de hacer lo que le dé la gana dado el poder que tiene, resulta que los problemas genéticos no son únicamente biológicos, sino filosóficos y éticos, fundamentales para la supervivencia de los habitantes de este planeta. En manos de meros biólogos lo que podemos tener pasado mañana es el sueño de Hitler hecho realidad: dividir la humanidad entre elites y rebaños, entre unos pocos amos y millones de esclavos. Por eso la transversalidad no habla sólo de transdisciplinaridad, porque no son sólo las fronteras entre los saberes las que se quedaron obsoletas, sino entre saberes y deberes, entre investigación y proyecto de sociedad. La transversalidad de los saberes apunta así hacia esos nuevos sujetos de la educación, cuyo desciframiento remite a lo que Antonio Machado recogió de labios de un campesino y lo puso en boca de ese alter suyo al que Ilamó Juan Mairena: «todo lo que sabemos lo sabemos entre todos». 


\section{SABERES INDISPENSABLES}

Una explícita transversalidad es la que moviliza a los saberes indispensables, que son aquellos que no siendo funcionalizables son socialmente útiles, pero no son tampoco saberes temáticos, pues operan unas veces sustentando y otras subvirtiendo los saberes temáticos. En su paradójico estatus los saberes indispensables, aunque se hallan ligados a materias históricas, no responden a las condiciones epistémicas ni a los operadores de funcionamiento de las disciplinas académicas. Estoy hablando de los saberes lógico-simbólicos, los saberes históricos y los saberes estéticos.

\subsection{SABERES LÓGICO-SIMBÓLICOS}

Los cambios por los que atraviesa nuestra sociedad en las condiciones de producción y de circulación de los saberes producen un fuerte autismo en la escuela-institución como reacción al desorden cultural que se vive en el ambiente, lo que a su vez se traduce en una gran dispersión cognitiva por parte de los alumnos: ¿quién sabe qué, por cuáles medios y con qué relevancia social? Frente a tal situación el maestro recurre a la imposición de un saber que no encuentra resonancia en el alumno, pero que éste se ve obligado a reproducir, o se pone a la escucha de lo que la dispersión y el desorden mental de sus alumnos significa y plantea a la institución escolar. Me estoy refiriendo a la exposición constante en que nos hallamos a una multiplicidad de símbolos y de información, de lenguajes y de escrituras. Con esta introducción busco situar lo estratégico del saber lógico-simbólico no sólo por hallarse en la base de lo que nuestra sociedad entiende por ciencia, sino por estar ligada a la lógica de las redes computacionales y sus hipertextualidades, a las que los más jóvenes están especialmente abiertos. Los saberes lógico-simbólicos, basados en el arte combinatorio de Leibniz, «especie de alfabeto de los conocimientos humanos que permite, mediante la combinación de sus letras y el análisis de las palabras compuestas de aquéllas, descubrir y juzgar todo lo demás», y en «un análisis lógico del razonamiento matemático o del pensamiento puro» (Frege), se ocupan de la estructura del argumento posibilitando un pensamiento cuya criticidad no sólo no se opone al rigor sino que hace de éste su otra base.

Con independencia del área científica o de la formación profesional de que se trate, la importancia de los saberes lógico-simbólicos reside en su sentido pragmático y en lo que hoy representan como hori- 
zontes de saber: su capacidad de forjar una mentalidad en consonancia con el mundo del conocimiento y con el de las tecnologías informáticas a partir de las destrezas lógicas que ambos requieren. Y es sólo desde el interior de esos saberes que es posible plantear sus límites y la necesidad social de otros tipos de saber.

\subsection{SABERES HISTÓRICOS}

Mientras los saberes lógico-simbólicos están en el ambiente y son dispositivos de organización del conocimiento hegemónico, los históricos se hallan devaluados y casi ausentes del entorno actual. Vivimos una fuerte deshistorización de la sociedad en beneficio del presente y de su valorización absoluta. No atravesamos sólo una merma de horizontes de futuro, también una peligrosa pérdida de memoria. Lo que no puede confundirse con la falta de memoria de los jóvenes, pues con frecuencia ese reclamo de los adultos tiene menos que ver con lo que les sucede a los jóvenes y mucho más con la fuerte nostalgia con la que los adultos confunden la memoria, pues recordar en términos sociales no es ir/huir al pasado, sino asumir el pasado de que está hecho el presente. Y sin conciencia histórica recordar nos lleva sólo al boom de la memoria comercializada que hoy espectacularizan las modas retro en arquitectura o en el vestido, o el auge de los anticuarios y de los museos. Hay un «arreglo kitch» en el que se pueden mezclar retazos del pasado sin la menor vinculación con sus contextos históricos. No se trata tampoco de promover una historia contemporánea que haga énfasis en el pasado reciente, sobre todo cuando lo que se valoriza es lo actual confundido con lo instantáneo.

Se trataría de encontrar claves en el pasado para identificar y descifrar las encrucijadas del presente. Lo que hacen de modo distinto las diversas culturas, en especial las indígenas, permeando con su pasado la experiencia del hoy y la del mañana. De lo que se trata es de superar la historia que encierra a los individuos en su aldea -local o nacional-, pero valorando al mismo tiempo las memorias locales y las minoritarias; de construir nuevas narrativas históricas plurales en las que quepan la memoria del lugar donde vivo, del país en el que estoy, del mundo al que pertenezco, y de abrir a los jóvenes a los diferentes ritmos y temporalidades de los pueblos y de las culturas, a entender que no todo pasa a la misma velocidad.

Saberes históricos serían aquellos capaces de interpelar la conciencia histórica, lo que significaría recuperar menos lo que pasó 
que aquello de lo que estamos hechos, sin lo cual no podemos saber ni qué ni quiénes somos. Necesitamos construir una historia que, partiendo de algunos hechos claves del presente cercano, nos permita situarlos en la escala más ancha del tiempo largo, de poner nuestro hoy en perspectiva, o sea, de des-naturalizar lo obvio y evitar los determinismos de toda especie, lo que implica al final un ejercicio de desestabilización del presente, para que haya horizontes y proyectos de futuro y no una eterna repetición de lo actual, para poder debatir sobre los futuros, y no sólo de aquellos predecibles a partir de las tendencias actuales sino de los alternativos, de los que realmente innovan.

\subsection{SABERES ESTÉTICOS}

Este tercer tipo de saberes indispensables y transversales podría llevar al antiguo y bello nombre de saberes de la sensibilidad, que era el significado griego del verbo aisthanesthai (sentir, percibir) y del adjetivo aisthêtikos: lo que atañe a la sensibilidad. Se trata de asumir los saberes que hacen parte de los modos y de las estructuras del sentir, lo que significa empezar a valorar como saber todo aquello que el racionalismo del pensamiento moderno relegó al campo de la imaginación y de la creación estéticas, tenido sólo por valioso por la corriente romántica. En efecto, los románticos fueron pioneros tanto en percibir los efectos degradantes de la revolución industrial como en valorizar las dimensiones de la vida destruidas por el progreso. Pero lo que propongo no es una vuelta al romanticismo, sino el reconocimiento de los saberes que entrañan las formas de lo expresivo, que pasan por el cuerpo, la emoción, el placer. Reconocer que la inteligencia es plural, como lo es la creatividad social en lo individual y en lo colectivo. Descifrar las prácticas en que se fusionan como nunca antes lo habían hecho el arte y la tecnología, pues también por la técnica pasan modalidades claves de percepción y cambios de la sensibilidad que anudan de forma innovadora el trabajo y el juego, lo real y lo virtual, lo imaginario y lo onírico.

Pensados así, estos saberes transversales (o como se llamaban antes: generales) crearán malestares profundos en las áreas especializadas de formación, pues entrañan un desdibujamiento de lo que está amarrado y ordenado de manera lineal, transformándolo en un conjunto intertextual polisémico y polifónico, ya que transversales son loa saberes que duran toda la carrera y toda la vida. Y deben movilizar a la vez otros saberes, que, como la geografía, ha dejado de ser para la juventud una mera cuestión de mapas y se desarrolla en dos sentidos: el de las 
interacciones humanas que posibilita la informática entre puntos del mundo no importa qué tan distantes se encuentren, y aquel otro que tiene que ver con la nueva geografía de los lenguajes musicales y corporales entrelazando culturas y tiempos muy alejados y diversos. Y movilización de saberes lingüísticos, que, en el caso del inglés, se hacen necesarios no sólo como la lingua franca del imperio, sino como el idioma de Internet, con el que nos ponemos en contacto con casi todo el mundo. Otra cosa es aprender a pensar en inglés, lo que exige incluir de forma indispensable su multiculturalidad.

\section{BIBLIOGRAFÍA}

BECK, U. (1998): La sociedad del riesgo, Barcelona, Paidós.

BouRdieU, P. (1972): Esquisse d'une théorie de la pratique, Ginebra, Droz.

Bourdieu, P. y PAsseron, J. C. (1970): La reproduction, París, Minuit.

BRUNNER, J. J. (2003): Educación e Internet ¿la próxima revolución?, Santiago, FCE.

Flacso.

- (1991): El nuevo pluralismo educacional en América Latina, Santiago,

CASTELLS, M. (2001): La galaxia internet, Barcelona, Plaza y Janés.

- (1998): La era de la información, vol.1, Madrid, Alianza.

CHARTIER, R. (2001): Lecteurs et lectures a l'âge de la textualité électronique, París, Centre Pompidou.

- (2000): Las revoluciones de la cultura escrita, Barcelona, Gedisa.

CERTEAU, Michel de (1980): L'invention du quotidien 2: arts de vivre, París, U.G.E-10/18.

GINZBURG, C. et al. (1983): Crisis de la razón: nuevos modelos en la relación entre saber y actividad humana, México, Siglo XXI.

Orden.

FREIRE, P. (1967): La educación como práctica de la libertad, Caracas, Nuevo

HABERmAS, J. (1990): El discurso filosófico de la modernidad, Madrid, Taurus.

ILLICH, I. (1971): Une société sans école, París, Seuil. 
Saberes hoy: diseminaciones, competencias y transversalidades Aires, Norma.

MARTín-BARBERO, J. (2002): La educación desde la comunicación, Buenos MEAD, Margaret (1971): Cultura y compromiso, Buenos Aires, Granica.

SOUSA SANTOS, B. de (2000): Crítica da razão indolente. Contra o desperdício da experiência, São Paulo, Cortez.

TEDEsco, J. C. (2000): Educar en la sociedad del conocimiento, Buenos Aires, FCE. 